\section{Summary of: Changes in dental health investment across the adolescent years}

\author{
C. J. Telford ${ }^{1}$ and C. O'Neill ${ }^{2}$
}

FULL PAPER DETAILS

${ }^{*} 1$ Queen's University Belfast, Centre for Public Health, School of Medicine, Dentistry and Biomedical Sciences, Belfast; ${ }^{2}$ Cairns School of Business and Economics, National University of Ireland Galway,

University Road, Galway, Ireland

${ }^{*}$ Correspondence to: Dr Claire J. Telford Email:drclairetelford@gmail.com

Refereed Paper

Accepted 1 March 2012

DOI: $10.1038 /$ sj.bdj.2012.413

${ }^{\circ}$ British Dental Journal 2012; 212: E13

Background Studies investigating investment in health across the life course are lacking. The aim of this study was to examine investment in dental health across adolescence. Methods Changes in dental health investment, as measured by dental registration (months) between when adolescents were aged 11/12 years compared to when they were 15/16-yearsold, were investigated using ordinary least squares (OLS) regressions. Adolescents aged 11 or 12 years in April 2003 in the Northern Ireland Longitudinal Study were included $(n=13,564)$. The overall change in registration and changes according to socio-economic status, highest educational attainment of household reference person, parental marital status, as well as the individuals' gender and number of siblings were examined. Within variable disparities at both age groups were also investigated. Results Average number of months registered with a dentist fell from 8.14 months (11/12 years old) to 7.38 months ( $15 / 16$ years old) ( $p$ <.001). No gender disparities existed when adolescents were aged 11/12 years but when adolescents were 15/16 years old, females had significantly higher registration than males (8.72 months:8.20 months; $p$ <0.001). Conclusions During the transition from childhood to adulthood, an individual's dental health may suffer as a result of a decline in registration rates with a dentist. This risk is likely to be greater among males than females. The role of children's services within dentistry should be reviewed.

\section{EDITOR'S SUMMARY}

Adolescence - I remember that. As well as the excitement of my own money from part-time jobs, 'decent' music, school subject choices also came the onslaught of mood swings, door-banging, tempers....for me anyway. Basically a growing up period in which we are introduced to a lifetime of making our own decisions. One of the most important responsibilities that comes with the autonomy of adolescence is the duty to take care of our own health. Personally, I'm not sure I was at all aware of the importance of this at the time.

This BDJ paper by Telford and O'Neill looks at the effect on dental health investment when children move from childhood (11/12-year-olds) to adolescence (15/16-year-olds) using dental registration as an indicator. To take care of oral health, suddenly adolescents are required to make sensible choices about what they eat and drink, phone to make appointments with their GDP and give up their valuable leisure time for regular check-ups. We must remember that as a child, generally, decisions about one's oral health are made by parents. Parents have the weight of life experience, possibly of their own sufferings from poor oral health, behind them and their decisions for their children. They are responsible agents likely to appreciate the offset of preventative investment versus future healthcare problems. The study looks at 13,564 adolescents in Northern Ireland to find out whether they continue to invest in their own oral health as they begin to make their own choices.

Studies looking at investment in health, particularly dental health, over the life course are lacking. Yet it is invaluable in order to identify sticking points where life is inclined to overtake investment in one's own health so that we can work to target a strong health message at these crucial junctures. The results in this study emphasise how important it is that we continually review the role of children's services in dentistry.

I think that one of the most interesting outcomes of this research is the striking gender difference - 16-year-old girls appear to invest more in their oral health than boys of the same age. Why is this? I urge you to read this valuable research article to find out.

The full paper can be accessed from the $B D J$ website (www.bdj.co.uk), under 'Research' in the table of contents for Volume 212 issue 9.

Ruth Doherty Managing Editor

DOI: 10.1038/sj.bdj.2012.372 


\section{TO ACCESS THE BDJ WEBSITE TO READ THE FULL PAPER:}

- BDA Members should go to www.bda.org.

- Click the 'login' button on the right-hand side and enter your BDA login details.

- Once you have logged in click the 'BDJ' tab to transfer to the BDJ website with full access.

IF YOUR LOGIN DETAILS DO NOT WORK:

- Get a password reminder: go to www.bda.org, click the login button on the right-hand side and then click the forgotten password link.

- Use a recommended browser: we recommend Microsoft Internet Explorer or Mozilla Firefox.

- Ensure that the security settings on your browser are set to recommended levels.

IF YOU HAVE NOT YET SIGNED UP TO USE THE BDA WEBSITE:

- Go to www.bda.org/getstarted for information on how to start using the BDA website.
IN BRIEF

- This paper examines changes in investment in oral health (as measured by dental registration) during adolescence and offers explanation for such changes.

- Identifies groups at risk of poorer oral health.

- Provides greater insight into adolescent registration for dental services and prompts a review of the role of adolescent dental services.

\section{COMMENTARY}

Grossman's model of health capital suggests that individuals actively invest in their own health, both as a consumption and investment commodity. The 'stock of health' produced leads to an improvement in health on consumption and impacts on an individual over their life course. This reduces the opportunity cost of falling ill both for the individual and the economy as a whole. In dentistry, an example of this would be following preventive advice and regularly attending a dentist for a routine check-up. Such an investment is argued to lead to an improvement in oral health, both now and in the future and reduce the disutility of the number of potential days with dental problems. In this interesting paper, Telford and O'Neill investigate the change in dental registration of adolescents in Northern Ireland. Compared to a baseline of eight months, the mean number of months of registration fell to seven months. The authors argue that the increasing autonomy that occurs in the transition from childhood to adulthood leads to a reduction in registration and that this in turn, could increase the risk of an individual's dental health suffering. In short, adolescents become less interested in investing in their own dental health.

Although this has been identified as a statistically significant result, it would be interesting to determine if this reduction in attendance led to a clinically significant increase in disease levels. In health economics, the demand for healthcare is in fact a derived demand, ie individuals seek health rather than healthcare per se and the link between a lack of dental attendance and the subsequent development of disease may not be directly causal. However, the authors correctly highlight this as a worry; that this may reflect an underlying trend towards disinvestment in adolescence. This is important given the reported impact of socio-economic status and parental education on attendance. Health literacy is a key component of the Grossman's model, increasing the efficiency of the use of an individual's 'stock of health'. In addition to a review of children's services; it would appear apt to provide alternative strategies to improve health that involve the greater use of prevention on a whole population level.

\section{Dr Paul Brocklehurst}

NIHR Clinician Scientist \&t Honorary SpR in Dental Public Health

School of Dentistry

University of Manchester

\section{AUTHOR QUESTIONS AND ANSWERS}

1. Why did you undertake this research? Adolescence is an important period in life when one begins to assert autonomy in decision making and these decisions can have direct implications on health. This study was undertaken to examine investment in health during adolescence and how it may change. The authors were also interested in examining how changes may occur according to gender or family characteristics such as socioeconomic status, family size and family type (married, co-habiting, lone parent etc). Identifying those less likely to invest in health allows an identification of those at risk of poor oral health. In doing such research it is also possible to identify the current role of publically funded dentistry in adolescence.

\section{What would you like to do next in this} area to follow on from this work?

In order to gain a more complete understanding of dental registration through childhood, this study should also be conducted in younger children. A further study could examine the effects of dental attendance on oral health. Ideally within such a model, other factors known to influence oral health would be controlled for it is likely a number of positive oral health behaviours are influenced by dental attendance. It may be useful to examine not only the adolescent time period but also early adulthood as the benefits of dental attendance or consequences of poor attendance may not be realised immediately. 